\title{
Engaging Post-Secondary Students And Older Adults In An Intergenerational Digital Storytelling Course
}

\author{
Jennifer Hewson, Ph.D., University of Calgary, Canada \\ Claire Danbrook, MSW, Alberta, Canada \\ Jackie Sieppert, Ph.D., University of Calgary, Canada
}

\begin{abstract}
A five day Digital Storytelling course was offered to Social Work students, integrating a three day workshop with older adult storytellers who shared stories related to the theme stories of home. A course evaluation was conducted exploring the Digital Storytelling experience and learning in an intergenerational setting. Findings from surveys distributed at the end of the course to students and storytellers revealed that students' knowledge of and interest in Digital Storytelling and its application was enhanced. The intergenerational component was positive for students and older adults. Students identified the intergenerational component as a highlight of the course which improved their awareness of older adult issues and knowledge of working with aging populations. Older adult participants enjoyed working with the students which increased their understanding of younger generations. This innovative course enhanced students' learning experiences, meriting consideration for the incorporation of intergenerational learning opportunities and Digital Storytelling into future social service and aging related courses to better prepare students for gerontological practice.
\end{abstract}

Keywords: Digital Storytelling; Intergenerational Programming; Older Adults; Post-Secondary Education

\section{INTRODUCTION}

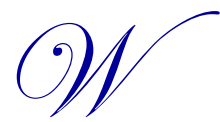
hile storytelling and narrative approaches are not new, Digital Storytelling is a unique storytelling process that has great potential for intergenerational practice. Digital Storytelling is a multimedia narrative process that incorporates text, images, video, sound effects, music and narration (Chung, 2007; Lambert, 2006; Oppermann, 2008; Robin, 2006). The process of creating a Digital Story is a carefully crafted one, commonly following the steps of having a story sharing circle, writing a script, gathering images, developing a storyboard, creating the story on a computer using movie making software, and sharing the story through screening (Freidus \& Hlubinka, 2002; Jakes, 2006; Kajder, 2004; Lambert, 2006; Ohler, 2006; Robin, 2008). Digital Stories are typically 2-3 minutes in length, and though short, can efficiently communicate compelling narratives that inform the viewer on a specific issue, concept or practice (Freidus \& Hlubinka, 2002; Jakes, 2006; Lambert, 2006; Oppermann, 2008; Robin, 2006). While stories can be created simply for personal use, the power of Digital Stories is in their use for promoting awareness about social issues and personal experiences such as homelessness, abuse, mental health, and aging as well as advocating for social justice and social change.

Digital Storytelling can be an innovative approach to teaching and meeting the diverse educational needs of a post-secondary student population (Gregory \& Steelman, 2008). It has been used in educational settings, from elementary to university, allowing its potential as a powerful teaching and learning tool to become recognized (Ohler, 2006; Oppermann, 2008; Robin, 2006; Robin, 2008; Sadik, 2008). The integration of Digital Storytelling into teaching has been described as a transformative process and potentially therapeutic given its self-reflexive nature (Benmayor, 2008). With such an engaging medium, students are active participants in a learning experience that integrates creative and critical processes (Benmayor, 2008; Jakes, 2006; Ohler, 2006; Sadik, 2008). In creating 
a Digital Story, students develop and apply a range of skills including writing, performance, editing, multimedia literacy, integration and construction of meaning, critical thinking, communication, and self-expression (Benmayor, 2008; Chung, 2007; Jakes, 2006). The opportunity to discover and use their voices to produce their own meanings, and recognize the context that shaped them, can be an empowering experience, especially for students who are marginalized or disadvantaged (Alexandra, 2008; Benmayor, 2008; Chung, 2007; Gregory \& Steelman, 2008; Jakes, 2006).

While there is literature about its application in educational settings and potential therapeutic implications, there is a lack of understanding about the use of Digital Storytelling with social service students as a curriculum tool and practice method when working with diverse and vulnerable populations. Given the increasing aging population and associated impacts for social service delivery, a timely application is with older adults. While storytelling with older adults has been described in the literature, the role of integrating Digital Storytelling into social service curriculum is unclear.

When learning about aging, the potential for a higher level of understanding can be developed through intergenerational practice. As defined by the Centre for Intergenerational Practice (2011), "Intergenerational practice aims to bring people together in purposeful, mutually beneficial activities which promote greater understanding and respect between generations and contributes to building more cohesive communities" (p. 4). Intergenerational programming has positive outcomes for both older adults and younger groups involved such as eliminating biases and stereotypes of different generations, enhancing communication and understanding, building strong links between generations, and preventing barriers from developing (Ayala, Hewson, Bray, Jones \& Hartley, 2007; Greengross, 2003; Larkin, 2004; Singleton, 2006; Thang, Kaplan \& Henkin, 2003).

Intergenerational learning in educational environments enables a sharing of knowledge between younger students and older generations (Greengross, 2003). Newman and Hatton-Yeo (2008) highlighted several global intergenerational learning opportunities in post-secondary environments. These examples showcase benefits, reciprocity and empowerment outcomes for these programs supporting the value of intergenerational learning opportunities. A body of literature exists which focuses on the role of intergenerational learning experiences as a way of better preparing students for future practice with older adults. Several authors have written about infusing gerontological social work curriculum with course content, activities, practicum, and service learning opportunities (e.g., Dorfman, Murty, Ingram \& Evans, 2002; Fenster, Zodikoff, Rozario \& Joyce, 2010; Hermoso, Rosen, Overly \& Tompkins, 2006; Joyner \& DeHope, 2008; Rogers, Gualco, Hinckle \& Baber, 2013; Singleton, 2006). These discussions contribute to an understanding of enhancing gerontological curriculum and preparation for working in the field of aging.

There is, however, a paucity of literature specifically on post-secondary curriculum with social service students and older adults learning together in a classroom environment with the intergenerational experience as a primary purpose of the course. The lack of literature on the use of Digital Storytelling as a curriculum tool with social service students focusing on aging, combined with the limited understanding of the potential for intergenerational courses in social service, post-secondary settings provides a unique opportunity for their integration to enhance curriculum and practice related to older adults.

\section{PURPOSE}

The purpose of this project was to facilitate an intergenerational Digital Storytelling course in the Faculty of Social Work at one Canadian University and assess the outcomes of the intergenerational experience for postsecondary students and older adult participants. The specific objectives were to explore: a) student experiences about learning Digital Storytelling and perceived value as a Social Work tool; b) students' perspectives about the intergenerational application with older adult story tellers; and c) older adults' perspectives about sharing their stories in an intergenerational setting.

A five day Digital Storytelling course was taught to eight Social Work students including five Bachelor of Social Work (BSW) students, two Master of Social Work (MSW) students, and one alumni. Two Faculty of Social Work instructors trained as Digital Storytelling facilitators led the course which was designed to provide students 
with an opportunity to learn about the history and development of Digital Storytelling; the elements of a Digital Story and the technical components involved in creating a story; and the potential for using this method for promoting awareness of social issues, giving voice to marginalized and vulnerable populations, and promoting social justice.

The course was offered in an intergenerational setting which included a three day workshop with seven older adult storytellers ranging in age from their late 50 s to early 70 s. While students did not have an opportunity to create their own stories, they learned about Digital Storytelling alongside the older adult participants, and assisted them with creating individual stories based on the theme "stories of home". Through assisting the older adults, students had the opportunity to identify diverse learner needs and develop basic workshop facilitator skills. In addition, the course was designed for students to develop increased awareness and understanding of older adult experiences and issues. An example of a Digital Story that was created is a story of a retired woman who moved from Asia to Canada during her early adult years. The story focused on what home meant to her as she questioned "belonging" to her country of origin and current residence. She selected photos related to where she had lived, her family and activities; included cultural music; and narrated her story of home. All of these elements were integrated into an emotional and thought provoking story of home using Final Cut Express movie making software. This story, along with others from the workshop, was shown at a public screening and conferences to promote awareness about aging and the power of Digital Storytelling as a curriculum, engagement, and advocacy tool.

\section{METHOD}

\section{Sample}

All seven older adults and seven of the eight students participated in a course evaluation. The study was approved by the University's ethics review board and all participants signed consent forms. Students were ensured that their participation in this study would not impact their grade or assessment of future academic or professional performance. Their surveys were not reviewed until after their grades had been submitted.

\section{Data Collection}

Two surveys consisting of closed and open ended questions were developed: one for the students and another for the older adult storytellers. A 17 item survey was distributed to students at the end the course. This survey consisted of seven Likert scale items and ten open-ended questions. Questions addressed student learnings about Digital Storytelling, their awareness of older adult issues, their experience and satisfaction with the intergenerational component, and workshop facilitation. A 22 item survey was distributed to the older adult storytellers at the end of the workshop. This survey consisted of 12 Likert scale items, and ten open-ended questions. Survey questions addressed the older adult's experience with the intergenerational component, their overall experience with the workshop, and their learning experience. For the purpose of this article, only data from questions regarding the intergenerational component were extracted from the older adult storyteller surveys.

\section{Data Analysis}

The responses from both students and older adult storytellers' surveys were analyzed separately. Qualitative data analysis was conducted for open ended questions and themes were identified for each question. Descriptive statistics were run for closed ended questions. Given the small number of completed surveys, manual analysis was conducted for both qualitative and quantitative data.

\section{FINDINGS}

\section{Student Perspectives: Knowledge and Learning about Digital Storytelling}

Students were asked a number of questions to assess their knowledge and learning about Digital Storytelling. The majority of students agreed or strongly agreed with statements about enhanced knowledge of Digital Storytelling and the application of Digital Stories. One student commented that the course could be 
"incorporated into core work/courses in the social work program". All students agreed that the instructors and facilitators demonstrated expertise in key elements of Digital Storytelling. When asked in what ways the course could be improved, students expressed a need for more preparation and learning about the expectations of the program and the computer software commenting, "students could learn about the program before they started to work with seniors", "students would have been more prepared... if they had done a story first".

When asked whether they learned facilitation skills that would assist with helping older adults create Digital Stories, the majority of students agreed. Students were also asked if there were any additional facilitation skills that they would like to have prior to assisting other older adults at an upcoming workshop. The majority of responses again highlighted students' need to become more experienced about the computer software through more training and experience, specifically on facilitation and working with older adults and application to social work. One student added the need for more awareness of English as a second language and cultural barriers.

Students were asked what they liked best about the course, and their responses highlighted learning about Digital Storytelling and the creative process involved. One student expressed that the workshop was a "great process to empower an individual to reflect on experiences". The students were asked what their greatest learning was as a result of taking this course, which generated diverse responses. Some students highlighted honing interpersonal skills such as supporting, listening, helping and making connections with older adults. Another student responded that she learned "how important it is to share your story", while others focused on the Digital Storytelling process including "the creative process", the "approach to creating a good story" and the "process of collecting artifacts... and connecting them to story".

The majority of students agreed and strongly agreed with statements asking about their interest in sharing what they learned in future workshops and specifically with other older adult participants. When asked how they thought they could apply their course learnings to other contexts, students responded that they felt they could apply their learning to "many different settings", or "working with any population". One student stated that Digital Storytelling "is a very empowering experience" and "the possibilit[ies] for application are ENDLESS" while another recommended that Digital Stories be used for "other marginalized groups who do not have a voice".

\section{Student Perspectives - Intergenerational Component}

Students were asked about their experiences of interacting with the older adult storytellers. Four students referred to the intergenerational component, including "working with", "learning from", and "getting to know the older adults" as what they liked best about the course. The students were asked what they learned from the intergenerational component of the course, and four responded that they learned a lot from the intergenerational group and the older adult participants, including: "their lives, issues, points of view", that they are "very independent and have many skills", that "we have many things in common", "learning patience", and "the importance of life development, transitions in life". Student responses reflected an overwhelmingly positive view of the intergenerational component, which is demonstrated in comments such as "working/spending time together made us all more ALIVE, connected", and it is a "blessing to work with intergenerational groups". The majority of students strongly agreed/agreed that the course enhanced their knowledge about working with older adults and they enjoyed the opportunity to assist older adults with telling their stories.

When asked in what ways the intergenerational component could be strengthened, students' responses reflected the need for more time to develop the bond and relationship between older adults and students with suggestions provided such as "some small exercises together...to build the bond and trust", "informal meet and greet before classes started", "longer than a week", and "more introduction time". Another issue that was identified by a couple of students was the need for more understanding of the process, expectations, and software so they would feel better prepared for assisting older adult storytellers. Some students suggested that "sharing my story with them", or having "an assignment that reflects the interactions between senior and student" could enhance the intergenerational component. One student felt that the facilitators could have better addressed older adults' needs in a workshop setting such as "the need for stretching", "room temperature" and "bigger font". 
Students were asked to reflect on whether the workshop experience enhanced their awareness of older adult issues, and in what ways. All but one student responded that their awareness of older adult issues was enhanced in terms of "cultural, generational, ethnicity...[and] health issues", that "although aging is a natural process some had concerns", "learned more about personal struggles", "the benefits and need for creative expression for elders", and that older adults "have a strong voice that deserves to be heard". One participant who disagreed explained that this was because she felt the "seniors that participated were not the average senior".

When students were asked if they thought that Digital Stories would help promote awareness about older adult issues, all participants responded positively with consensus that Digital Stories promote awareness by allowing for the sharing of life stories and education on older adult issues stating, "it has a great potential to promote awareness about many areas of seniors' issues such as domestic violence, coping with illness, caregiver support, hospice life stories"; "although seniors are advancing in years, they maintain their vitality...[and are] very active in their communities"; "empowering, meaningful and great educational tools"; and "could be used very well in participatory research projects".

\section{Intergenerational Component - Older Adult Perspectives}

The older adult storytellers' responses to statements on the intergenerational component of the workshop revealed that the majority strongly agreed with statements about enjoying working with the students and feeling comfortable sharing the stories. Older adult participants were asked what was learned from the intergenerational component of the workshop. Overall, the responses reflected a positive perception of the intergenerational component, indicating that they learned that younger students were "understanding", "supportive", "willing and helpful", and "not condescending". Overwhelmingly the storytellers expressed learning that they were comfortable working with the younger generation and were able to share and learn from each other. In the words of one participant, "story-telling bridges gaps between the generations". When the older adults were asked in what ways the intergenerational component could be strengthened, most noted the need for increasing the opportunities to share and get to know each other. They suggested that this could be done through activities, one on one time, time together before the course begins, or having students tell their stories. One participant also suggested that the intergenerational component could be strengthened through the "involvement of different nationalities".

\section{DISCUSSION}

Offering this Digital Storytelling course was innovative in terms of both the topic and intergenerational application. This had not been done before at this university and there was no academic evidence of such a course being offered in other postsecondary institutions at the time. This project accomplished the objective of enhancing students' learning of Digital Storytelling and knowledge of the potential application of this approach for Social Work practice with older adults. The students' responses revealed they enjoyed and benefited from learning about Digital Storytelling and participating in the creative process, and found the course to be a positive, powerful experience accompanied by much learning. Overall, the majority of students agreed that their knowledge of the Digital Storytelling process and its application for Social Work was enhanced, and that they would be interested in applying and sharing their learning in the future with older adults and other populations. The students expressed that they gained technological and creative skills related to storytelling.

Something to consider for future Digital Storytelling course offerings would be to extend the course over several weeks or a term rather than a block week in order to provide students with more familiarity with the software so that they can effectively use the technology and share their expertise with others. The challenge of lack of proficiency with technology and software is highlighted in the literature on teaching Digital Storytelling and points to an important implication for the design of successful Digital Storytelling courses for the future. The findings from the student surveys confirm the suggestion in the literature that students need extra support and time for technical assistance when integrating new technologies into course content (Benmayor, 2008; Oppermann, 2008; Robin, 2006; Robin, 2008; Sadik, 2008).

While learning and sharing in an intergenerational context was considered to be a positive experience for both students and older adults, the findings showed that this aspect could be further enhanced through extending the 
time spent together in order to foster relationships and build trust prior to engaging in the storytelling experience. This is an important insight about not rushing the process to meet practical requirements. Offering the course as a block week rather than over a full term limited the ability to fully develop intergenerational relationships and, given the personal nature of the activity and engaging with a potentially vulnerable population could have compromised the essence of the storytelling experience. This is something that must be closely examined for future intergenerational Digital Storytelling opportunities.

Comments from the students indicate that while they benefited from supporting storytellers, it would be helpful to have first been a storyteller to have enhanced technological proficiency and knowledge of the outcome. Trained Digital Storytelling facilitators are required to create their own Digital Story to have experience as a storyteller prior to learning how to facilitate. It should be noted that the intention of the course and workshop was to present an application whereby the students could assist older adults with the process, not to be trained as certified facilitators. Extending the course over a longer period of time would have provided an opportunity for students to further develop facilitation skills required to assist facilitators and storytellers with all stages of creating a Digital Story. This was an area that was identified by a number of students as an opportunity for enhancement, and is indeed a difficult thing to practice, especially for novice assistants who are supporting older adults with little or no experience with such technology. In addition, most students had little or no prior knowledge of working with older adults, and responses highlighted the need for more learning in this area. By extending the course, this aspect could also be improved upon, with further opportunities to devote to the specific requirements of working with this population (e.g., need for breaks; shorter days; vision, hearing, and mobility considerations) and also to explore unique facilitation skills that would be needed for other populations.

The course was designed to enhance students' understanding of older adult issues and the evaluation specifically explored students' perspectives about the application with older adult storytellers. While applying Digital Storytelling to gerontology could have simply been discussed, learning through working with older adult storytellers had a powerful impact that curriculum content alone may not have been able to provide. The students felt that their awareness of older adult issues and knowledge about working with older adults was enhanced and that they benefited from being given this opportunity to share in the older adults' lived experiences. These findings support the value of Digital Storytelling for learning and sharing across cultures and communities, and for opening dialogue on marginalized issues (Alexandra, 2008; Benmayor, 2008).

The course provided opportunities for students to not only learn about experiences and issues of older adults but to engage in collaborative learning and sharing. The findings indicate that this was an enjoyable and insightful experience for both students and older adults, with many indicating that it was what they liked best about the course. These findings provide further support for existing literature which highlights the value of intergenerational opportunities for both generations in providing positive, mutually beneficial experiences (Ayala, Hewson, Bray, Jones \& Hartley, 2007; Greengross, 2003; Larkin, 2004; Singleton, 2006; Thang, Kaplan \& Henkin, 2003). In spite of the aging population, very few gerontology courses are offered in this particular school, which may also be the case at other universities. The fact that such highly positive feedback was obtained from both students and older adults engaging in such an opportunity within a post-secondary educational setting suggests that it may be beneficial to include an intergenerational application in Social Work curricula which supports existing literature about ways to better prepare students for gerontological Social Work practice (Dorfman, Murty, Ingram \& Evans, 2003; Fenster, Zodikoff, Rozario \& Joyce, 2010; Hermoso, Rosen, Overly \& Tompkins, 2006; Joyner \& DeHope, 2008; Rogers, Gualco, Hinckle \& Baber, 2013; Singleton, 2006).

Older adults as a group are considered vulnerable given potential risk factors related to, for example, health, income, housing, and transportation as well as limited opportunities for promoting awareness of their experiences and needs. As noted by one student, the older adults who participated in the course were not typical of those who social work students may likely engage in practice with given that they were able to come to a university setting to participate in a workshop using computers for three intensive days. As a way to enhance the gerontology learning experience, students would also benefit from opportunities to interact with subpopulations of older adults with higher levels of risk and in diverse settings to obtain an understanding of specific issues they may face which could be advocated for using Digital Storytelling. When infusing intergenerational courses into social work programs, social justice, diversity, and advocacy must be at the forefront of curriculum discussions. 


\section{CONCLUSION}

This study has highlighted conclusions relevant to the development and utility of future intergenerational programming in post-secondary settings, the teaching of Digital Storytelling and its use as an innovative educational tool, and its potential application to social service related practice with older adults.

The very processes of engaging in conversations about "story", making decisions about what constitutes a good story, how a story comes together, and how such stories can change practice are valuable. Through the process of creating (or helping to create) a Digital Story, students may develop a deeper understanding of the important narratives that guide the lives of individuals they will encounter during their careers. In addition, by participating in Digital Storytelling, students get to experience the creation of a product that can be used in multiple ways, such as teaching, advocacy, and communication. This too can help shape the ways they decide to practice. It is clear that Digital Storytelling has value for use in Social Work participatory research projects. The experience of this Digital Storytelling course suggests the possibility of further developing the approach as an alternative to more traditional interventions in Social Work, which remains an important opportunity for future research.

Indeed, an important part of the Digital Storytelling course focused on the students' role in facilitating the Digital Storytelling process. Social work students regularly receive training in effective facilitation, individual interviewing, and group processes; however, the effective facilitation of "storytelling" as both a process and form of practice is rarely focused on in Social Work education. The responses offered by students in this course suggest that students may be eager to learn specific storytelling skills as a way to enhance their professional practice. While Digital Storytelling is one example of such facilitation, a broader experience and understanding with a range of storytelling or narrative forms may be valuable learning for social service students.

Finally, the positive responses from student and older adult participants on the intergenerational component highlight the value and benefit of incorporating intergenerational programming and learning into post-secondary courses. With the increasing aging population, post-secondary institutions will need to explore ways to develop curricula to add to or improve upon gerontological content in order to prepare future practitioners for work with older adults. This study suggests that Digital Storytelling combined with intergenerational programming have great potential for social service education given the wealth of experiences and stories that older adults have to share with students, and the technological skills possessed by students of the younger generation. However, it also suggests that educators should continue their search for creative ways to blend hands-on, creative ways to structure intergenerational learning opportunities for post-secondary students and older adults. It is the actual experience of intergenerational interaction from which students learn best, rather than discussions about intergenerational programming.

\section{AUTHOR INFORMATION}

Dr. Jennifer Hewson's research interests include social participation, isolation and inclusion; age-friendly cities; and policies and practices related to program and service delivery in the older adult sector. She has been very involved with committees related to creating an age-friendly Calgary, community engagement and older adults, and enhancing older adult service provision. Dr. Hewson's teaching has focused on community based research, participatory action research, mixed methods research, and evaluation. She has integrated Digital Storytelling and Photo Voice into her research designs and teaching. Email: jahewson@ucalgary.ca

Claire Danbrook is a graduate of the Master of Social Work Program, University of Calgary, Alberta, Canada (2010). Her Master of Social Work studies specialized in gerontology, with an interest in topics including aging, health care, intergenerational relationships, and Digital Storytelling. She is currently practicing clinical social work in a health care setting. Email: danbrook.claire@gmail.com

Dr. Jackie Sieppert's research interests include community development with seniors, dynamics of successful collaboration, and Digital Storytelling. He was involved with the Elder Friendly Communities Program and played a lead role in the Faculty of Social Work's Digital Storytelling Program. As the Dean of the Faculty of Social Work, Dr. Sieppert is very involved in curriculum and program design for undergraduate and graduate education. Email: sieppert@ucalgary.ca 


\section{REFERENCES}

Alexandra, D. (2008). Digital storytelling as transformative practice: Critical analysis and creative expression in the representation of migration in Ireland. Journal of Media Practice, 9(2), 101-112.

Ayala, J. S., Hewson, J. A., Bray, D., Jones, G., \& Hartley, D. (2007). Intergenerational programs: Perspectives of service providers in one Canadian city. Journal of Intergenerational Relationships, 5(2), 45-60.

Benmayor, R. B. (2008). Digital storytelling as a signature pedagogy for the new Humanities. Arts \& Humanities in Higher Education, 7(2), 188-204.

Centre for Intergenerational Practice. (2011). A Guide to Intergenerational Practice. Retrieved from $\mathrm{http} / / / \mathrm{www} . c e n t r e f o r i p . o r g . u k / r e s /$ documents/publication/BJFGuidetoIPV.pdf

Chung, S.K. (2007). Art education technology: Digital storytelling. Art Education, 60(2), 17-22.

Dorfman, L. T., Murty, S., Ingram, J. G., \& Evans, R. J. (2002). Incorporating intergenerational service-learning into an introductory gerontology course. Journal of Gerontological Social Work, 39(1/2), 219-240.

Fenster, J., Zodikoff, B., Rozario, P., \& Joyce, P. (2010). Implementing a gero-infused curriculum

in advanced-level MSW courses in health, mental health and substance abuse: An evaluation. Journal of Gerontological Social Work, 53(7), 641-653.

Freidus, N., \& Hlubinka, M. (2002). Digital storytelling for reflective practice in communities of learners. SIGGROUP Bulletin, 23(2), 24-26.

Greengross, S. (2003). Intergenerational programmes as a global approach to social issues. Journal of Intergenerational Relationships, 1(1)11-13.

Gregory, K., \& Steelman, J. (2008). Cresting the digital divide. Community College Journal of Research and Practice, 32, 880-882.

Hermoso, J., Rosen, A. L., Overly, L., \& Tompkins, C. J. (2006). Increasing aging and advocacy competency.

Journal of Gerontological Social Work, 48(1/2), 179-192

Jakes, D. S. (2006). Capturing stories, capturing lives: An introduction to digital storytelling. Retrieved from http://www.jakesonline.org/storytelling.htm.

Joyner, M., \& DeHope, E. (2008). Transforming the curriculum through the intergenerational lens. Journal of Gerontological Social Work, 48(1/2), 127-137.

Kajder, S. B. (2004). Enter here: Personal narrative and digital storytelling. The English Journal, 93(3), 64-68.

Lambert, J. (2006). Digital Storytelling: Capturing Lives, Creating Community. Berkeley, CA: Digital Diner Press.

Larkin, E. (2004). Introduction. Journal of Intergenerational Relationships, 2(3/4), 1-3.

Newman, S., \& Hatton-Yeo, A. (2008). Intergenerational learning and the contributions of older people. Ageing Horizons, 8, 31-39.

Ohler, J. (2006). The world of digital storytelling. Learning Through the Digital Age, 63(4), 44-47.

Oppermann, M. O. (2008). Digital storytelling and American studies: Critical trajectories from the emotional to the epistemological. Arts \& Humanities in Higher Education, 7(2), 171-187.

Robin, B. R. (2008). Digital storytelling: A powerful technology tool for the 21 st century classroom. Theory Into Practice, 47, 220-228.

Robin, B. R. (2006). The Educational Uses of Digital Storytelling. Art and Teacher Education Annual.

Rogers, A. T., Gualco, K. J., Hinckle, C., \& Baber, R. L. (2013). Cultivating interest and competency in gerontological social work: Opportunities for undergraduate education. Journal of Gerontological Social Work, 56(4), 335-355.

Sadik, A. (2008). Digital storytelling: A meaningful technology-integrated approach for engaged student learning. Education Technology Research Development, 56, 487-506.

Seedsman, T. A. (2007). Supporting intergenerational relationships: A role for universities. Journal of Intergenerational Relationships, 5(3), 83-98.

Singleton, J. L. (2006). Infusing gerontology throughout the BSW curriculum. Journal of Gerontological Social Work, 48(1/2), 31-46.

Thang, L. L., Kaplan, M. S., \& Henkin, N. Z. (2003). Intergenerational programming in Asia: Converging diversities toward a common goal. Journal of Intergenerational Relationships, 1(1), 49-69. 